\title{
Creating Learning Material from Web Resources
}

\section{Katrin Krieger}

Otto-von-Guericke-Universität Magdeburg, Germany

PhD supervisor: Prof. Dr. Dietmar Rösner

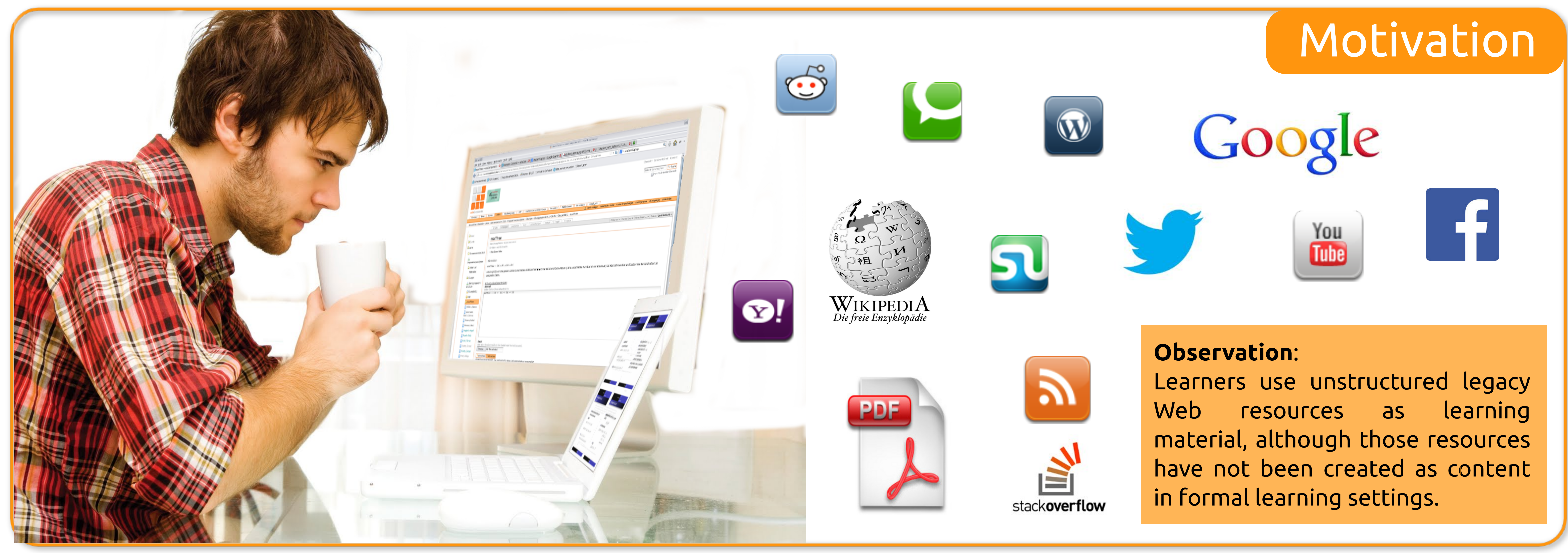

How can Web resources be structured and enriched with metadata such that they can be linked to e-learning contexts and act as learning material?

Haskell (programming
language)

\section{Linked Learning Items}

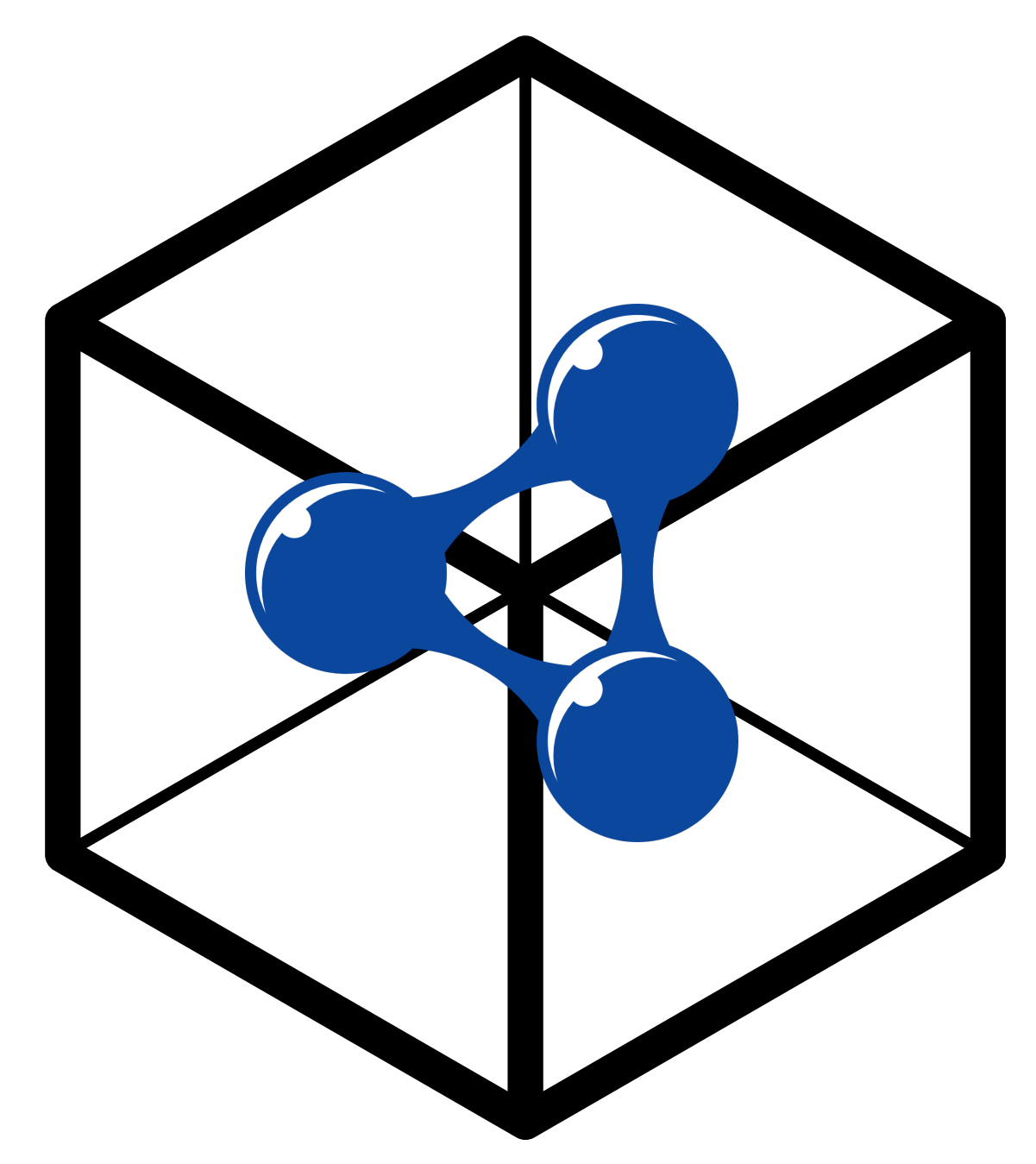

We create Linked Learning Items (LLI) and make them available as Linked Data. The LLIs contain data from the Web resource, its corresponding semantic fingerprint, and the gathered educational metadata.

These data packages can then be integrated directly in Web-based learning management systems (LMS) and offer learners the opportunity to access this learning material right from within the recent learning context. 